\title{
The protective effect of resveratrol against risperidone-induced liver damage through an action on FAS gene expression
}

\author{
Sebile Azirak ${ }^{1}$, Sedat Bilgic ${ }^{1}$, Deniz Tastemir Korkmaz ${ }^{1}$, Ayşe N. Guvenc ${ }^{1}$, Nevin Kocaman ${ }^{2}$ \\ and Mehmet K. Ozer ${ }^{3}$ \\ ${ }^{1}$ University of Adiyaman, Vocational School of Health Services, Adiyaman, Turkey \\ ${ }^{2}$ University of Firat, Department of Histology, Faculty of Medicine, Elaziğ, Turkey \\ ${ }^{3}$ University of Adiyaman, Department of Pharmacology, Faculty of Medicine, Adiyaman, Turkey
}

\begin{abstract}
The purpose of the study is to examine the protective effect of resveratrol on the fatty acid synthase gene expression against the side-effects of risperidone in an experimental model in rat liver. In this study, thirty-five female Spraque-Dawley rats were divided into five groups $(n=7)$ : Control, RIS ( $2 \mathrm{mg} / \mathrm{kg}$ risperidone daily), RSV1 ( $2 \mathrm{mg} / \mathrm{kg}$ risperidone $+20 \mathrm{mg} / \mathrm{kg}$ resveratrol), RSV2 ( $2 \mathrm{mg} / \mathrm{kg}$ risperidone $+40 \mathrm{mg} / \mathrm{kg}$ resveratrol), and RSV3 group ( $2 \mathrm{mg} / \mathrm{kg}$ risperidone $+80 \mathrm{mg} /$ $\mathrm{kg}$ resveratrol). On treatment day 15 , liver tissue was taken for analysis. The resveratrol treatment significantly reduced weight gain as opposed to the risperidone administration. Moreover, the fatty acid synthase gene expression level increased significantly in RSV1 group $(p=0.011)$. In addition, resveratrol enhanced the total antioxidant status, high-density lipoprotein cholesterol levels and decreased alanine aminotransferase, aspartate aminotransferase, total cholesterol, gamma glutamyl transpeptidase, low density lipoprotein cholesterol, oxidative stress index, triglycerides, and total oxidant status levels significantly $(p<0.05)$. In conclusion, this study revealed that treatment with resveratrol might protect liver tissue against the side-effects of risperidone over fatty acid synthase gene expression. Resveratrol could be an effective course of therapy for enhancing therapeutic efficacy.
\end{abstract}

Key words: Risperidone - Resveratrol - Fatty acid synthase - Liver - Apoptosis

\begin{abstract}
Abbreviations: AAPs, atypical antipsychotics; ALT, alanine aminotransferase; AST, aspartate aminotransferase; FAS, fatty acid synthase; GGT, gamma glutamyl transpeptidase; HDL, high-density lipoprotein cholesterol; HMGCR, 3-hydroxy-3-methylglutaryl-coenzyme A reductase; HMGCS1, 3-hydroxy3-methylglutaryl-coenzyme A synthase-1; LDL, low density lipoprotein cholesterol; OSI, oxidative stress index; RIS, risperidone; RSV, resveratrol; SREBP, sterol regulatory element binding proteins; TAS, total antioxidant status; $\mathrm{TCH}$, total cholesterol; TG, triglyceride; TOS, total oxidant status; TUNEL, terminal deoxynucleotidyl transferase dUTP nick end labeling.
\end{abstract}

\section{Introduction}

Atypical antipsychotics (AAPs) have been used in the treatment of schizophrenia. Risperidone (RIS) is an AAPs prescribed for the treatment of bipolar disorder, schizophrenia, depression, and autism (Keck et al. 2000). On the other hand, AAPs are associated with metabolic syndrome

Correspondence to: Sebile Azirak, University of Adiyaman, Vocational School of Health Services, Adiyaman, Turkey

E-mail: sazirak@adiyaman.edu.tr (including weight gain, dyslipidemia, hyperglycemia, type II diabetes mellitus, insulin resistance) and cardiovascular disease (Bou-Khalil 2012). However, the use of RIS has been restricted due to systemic side effects. Furthermore, RIS is the second most prescribed antipsychotic drug and causes significant changes in the metabolic parameters and weight gain in patients (Rummel-Kluge et al. 2010).

The latest studies have shown that these drugs can change glucose and lipid metabolism unrelated of any effect on neurotransmitter receptors on expression on the periphery. Cholesterol and fatty acid biosynthesis transcriptionally activate by 
antipsychotic drugs in cultured human glioma cells, including fatty acid synthase (FAS), HMGCR (3-hydroxy-3-methylglutaryl-coenzyme A reductase), HMGCS1 (3-hydroxy3methylglutaryl-coenzyme A synthase-1), and SREBP (Sterol regulatory element binding proteins) (Ferno et al. 2005).

FAS is a multifunctional protein enzyme encoded by the Fas gene that chiefly catalyzes fatty acids and regulates lipid metabolism (Wakil 1989). The highest expression of FAS has been reported in hepatic tissues. Therefore, fatty acid production pathway in the liver tissue facilitates surplus energy storage and circulating triglyceride (TG) rich lipoproteins (Jensen-Urstad and Semenkovich 2012). The liver performs a considerable role in energy intake and the regulation of lipid metabolism. It has been suggested that antipsychotic drug-related lipogenic effects have metabolic side effects in the liver (Lauressergues et al. 2010). On the other hand, FAS is organized nutritionally and hormonally (Sul and Wang 1998) to contribute to weight gain and the development of obesity (Mobbs and Makimura 2002). More recent studies have demonstrated that RIS significantly increases expression of the Fas gene in rat hepatocyte cultures (Lauressergues et al. 2011).

Nowadays, medicinal plants are a major source of drug. The extensive use of herbal compounds has encouraged scientists to investigate therapeutic properties on health. Resveratrol (RSV) is a natural phytoalexin that exists in many different plants, especially in grapes (Pal et al. 2003). Phytoalexins are secondary constituents against UV rays and damage and infections in plants (Ozelci et al. 2007). RSV has antioxidant activity that prevents DNA damage and lipid peroxidation in the cell membrane. RSV has been indicated to have broad spectrum benefits on human health on, for example the hepatic, nervous, coronary, and cardiovascular systems (Martin et al. 2004). In addition, RSV is a natural compound and has been shown to exert protective effects on the liver preventing lipid accumulation. Because of the high effect and low toxicity of RSV upon human health, it is a hopeful alternative to traditional therapeutic drugs.

To our knowledge, there is no report regarding the protective and therapeutic effects of RSV against the effect of RIS over Fas gene expression. Thus, the objective of our work was to research the possible useful effect of oral supplementation with RSV against the effect of RIS over Fas gene expression. To reach our target, we investigated genetic, biochemical, and histological analyses on rats.

\section{Materials and Methods}

\section{Chemicals}

RIS was purchased from Johnson \& Johnson (USA). RSV (trans-3,4,5-trihydroxystilbene, $\geq 98 \%$ ) was purchased from Carl-Roth ${ }^{\circledast}$ (Germany).
Animals

Thirty-five female Sprague Dawley rats (12-16-week-old) initially weighing 220-260 g were used in our study. These rats were acquired from the Experimental Research Center of Firat University. The rats kept under standard conditions: 12:12 h light/dark-cycles. Food and tap water were provided ad libitum. The care and follow-up of the rats was done in this center. All procedures and protocols were conducted in accordance with the Ethical Committee of the Firat University Faculty of Medicine (Protocol \# 2016/41).

\section{Experimental design}

All rats were randomly reserved into five groups (seven per group) as follows: Control group (saline solution), RIS group (2 mg/kg RIS), RSV1 group ( $2 \mathrm{mg} / \mathrm{kg}$ RIS and $20 \mathrm{mg} / \mathrm{kg}$ RSV), RSV2 group ( $2 \mathrm{mg} / \mathrm{kg}$ RIS and $40 \mathrm{mg} / \mathrm{kg}$ $\mathrm{RSV}$ ), and RSV 3 group ( $2 \mathrm{mg} / \mathrm{kg}$ RIS and $80 \mathrm{mg} / \mathrm{kg} \mathrm{RSV}$ ). The doses of RIS ( $2 \mathrm{mg} / \mathrm{kg}$ once a day for two weeks) and the doses of RSV (20, 40, and $80 \mathrm{mg} / \mathrm{kg}$ body weight/day for two weeks) were administered by gastric tube each day between 8:00 and 9:00. The doses of RIS (Zhang et al. 2007) and RSV (Zhao et al. 2014) were selected on the basis of previous study results.

Weights were recorded at the beginning and the end of the study. The rats' venous blood samples were collected. The animals were euthanized by exsanguination with diethyl ether anesthesia on the last day of the second week. The entire liver was excised and kept at $-86^{\circ} \mathrm{C}$ till analysis.

\section{Biochemical analysis}

Blood samples were collected to determine liver enzyme activity, and serum samples were separated by centrifuge at $2800 \times g$ for $15 \mathrm{~min}$; then, the samples were divided in Eppendorf tubes, and stored at $-86^{\circ} \mathrm{C}$ till biochemical analysis.

One of the samples was used for measuring serum levels of high-density lipoprotein cholesterol (HDL), total cholesterol (TCH), and TG using routine enzymatic methods with an Olympus 2700 analyzer (Olympus Diagnostica GmbH, Hamburg, Germany). Low density lipoprotein cholesterol (LDL) levels were calculated using Friedewald's formula. Standard liver function tests known as markers of liver injury, alanine aminotransferase (ALT), aspartate aminotransferase (AST) and gamma glutamyl transpeptidase (GGT) were measured using an autoanalyzer.

Another of the samples were used for measuring total antioxidant status (TAS), total oxidant status (TOS), and oxidative stress index (OSI) levels spectrophotometrically using the Erel method. Serum TAS and TOS levels were measured with kits (REL Assay Diagnostics, Gaziantep, 
Turkey). OSI value was calculated using the formula OSI = TOS/TAS (Erel 2004, 2005; Harma et al. 2005).

\section{Real-time PCR analysis}

Livers of rats were taken and divided. One of the samples of livers were stored in formaldehyde for TUNEL staining, and another of the samples of livers were stored at $-86^{\circ} \mathrm{C}$ until further analysis. Thirty mg of frozen liver tissues were homogenized in $500 \mu \mathrm{l}$ Tissue Lizis Buffer for 1 min using homogenizer (Bioprep-24, Allsheng). Total RNA was obtained from liver samples using an ExiPrepTM Tissue Total RNA isolation kit (Bioneer, K-3325). The RNA concentration was determined from absorbance at 230-260 nm and 260/280 nm using a NanoDrop spectrophotometer (Denovix DS-11). The results were then reversely transcribed into cDNA using the AccuPower ${ }^{\circledR}$ RT PreMix (Bioneer, K-2041) according to the manufacturer's instructions.

Real-Time PCR was performed using AccuPower GreenStar qPCR PreMix according to the manufacturer's instructions (Bioneer, Cat No: K-6210). The level of mRNA expression of Fas genes as detected using the ExiCyclerTM96 Real-Time Quantitative PCR system (Bioneer). The PCR reactions were performed as follows: $95^{\circ} \mathrm{C}$ for $5 \mathrm{~min}$, followed by 45 cycles at $95^{\circ} \mathrm{C}$ for $15 \mathrm{~s}$, and then $60^{\circ} \mathrm{C}$ for $25 \mathrm{~s}$. The sequences primers used were: Forward, 5'AGGTGCTAGAGGCCCTGCTA-3'; Reverse, 5'-GTGCACAGACACCTTCCCAT-3' (Bioneer, S-1001) (Ji et al. 2011; Fukunishi et al. 2014). The levels of each gene expression were calculated by the $2^{-\Delta \Delta \mathrm{Ct}}$ method.

Terminal deoxynucleotidyl transferase dUTP nick end labeling (TUNEL) assay

TUNEL staining was designed for the detection of apoptotic cells in liver tissue samples. The sections taken from the paraffin blocks at a thickness of $5 \mu \mathrm{m}$ were taken into the polylysine lamella. Apoptotic cells were identified using the ApopTag Plus Peroxidase In Situ Apoptosis Detection Kit (Chemicon, cat no: S7101, USA) according to the manufacturer's protocol.
Preparations were analyzed and photographed by a research microscope (Leica DM500). In the evaluation of the TUNEL staining, Harris hematoxylin-stained nuclei were normalized, and cells demonstrating brown staining were evaluated as apoptotic. In ten randomly selected areas, the sections were analyzed at $400 \times$ magnification (Tas et al. 2015), and at least 500 normal and apoptotic cells were counted. The apoptotic index (AI) was calculated by the ratio of apoptotic cells to total (normal + apoptotic) cells. The degree of TUNEL staining was scored semiquantitatively as 0 (none), 1 (light), 2 (medium), and 3 (intense) (Can et al. 2015).

\section{Statistical analysis}

Statistical analyses were performed using Statistical Package 16.0 (SPSS, Chicago, IL, USA). The experimental data were expressed as mean \pm standard error of mean (SEM). The Shapiro-Wilk test was used to determine the normality of variables in the groups. For the comparison of the mean weight of all groups, a paired T-test was performed. The groups were compared with the paired-samples T-test at the beginning and the end of the treatment. Two-way ANOVA was used to test the effect of RIS (control vs. RIS) and treatment (untreated vs. treated with RSV) as well as their interaction. The histopathological analysis was expressed as the means \pm standard deviation (SD). The Mann-Whitney $U$ test and the Student's $t$-test were used for statistical analysis. The significance was acceptable to a level of $p \leq 0.05$.

\section{Results}

\section{Effects of RIS and RSV on weight gain/loss}

Body weight measurements showed that, during the 14 days, weights increased in control, RIS, RSV1 and RSV3 groups, but in RSV2 group weight decreased (Table 1). Overall, in the Control, RIS, and RSV1 groups $(p<0.05)$ weight gain was statistically significant. On the other hand, the fact that

Table 1. Body weight of experimental rats before and after administrations of risperidone and resveratrol

\begin{tabular}{lccccc}
\hline \multirow{3}{*}{$\begin{array}{l}\text { Body weight } \\
(\mathrm{g})\end{array}$} & \multicolumn{5}{c}{ Group } \\
\cline { 2 - 5 } & Control & RIS & RSV1 & RSV2 & RSV3 \\
\hline Initial & $238.28 \pm 7.53$ & $234.57 \pm 7.27$ & $225.28 \pm 4.16$ & $232.40 \pm 3.55$ & $244.80 \pm 9.88$ \\
Final & $252.85 \pm 7.46$ & $248.00 \pm 5.86^{\mathrm{a}}$ & $233.71 \pm 3.68^{\mathrm{b}}$ & $228.80 \pm 5.25^{\mathrm{c}}$ & $249.80 \pm 9.42^{\mathrm{d}}$ \\
\hline
\end{tabular}

Values are expressed as mean \pm SEM $(n=7)$. The groups were compared with the paired-samples T-test at initial and final of the treatment. ${ }^{\mathrm{a}} p<0.005,{ }^{\mathrm{b}} p<0.005,{ }^{\mathrm{c}} p=0.071,{ }^{\mathrm{d}} p=0.537 v$ s. corresponding initial body weight. RIS group, rats treated with $2 \mathrm{mg} / \mathrm{kg}$ risperidone; RSV1 group, rats treated with $2 \mathrm{mg} / \mathrm{kg}$ risperidone and $20 \mathrm{mg} / \mathrm{kg}$ resveratrol; RSV2 group, rats treated with $2 \mathrm{mg} / \mathrm{kg}$ risperidone and $40 \mathrm{mg} / \mathrm{kg}$ resveratrol; RSV3 group, rats treated with $2 \mathrm{mg} / \mathrm{kg}$ risperidone and $80 \mathrm{mg} / \mathrm{kg}$ resveratrol. 


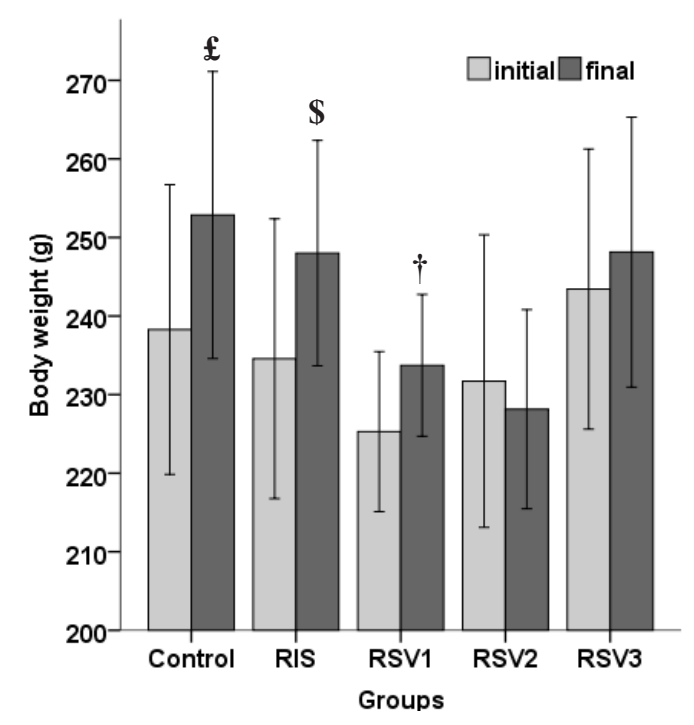

Figure 1. Changes in the body weight experimental rats before and after administrations of risperidone and resveratrol. Values are expressed as mean \pm SEM $(n=7)$. The groups were compared with the paired-samples T-test at the initial and final of the treatment. $\mathfrak{E , \$ , \dagger} p<0.05 v s$. corresponding initial value. RIS group, rats treated with $2 \mathrm{mg} / \mathrm{kg}$ risperidone; RSV1 group, rats treated with $2 \mathrm{mg} / \mathrm{kg}$ risperidone and $20 \mathrm{mg} / \mathrm{kg}$ resveratrol; RSV2 group, rats treated with $2 \mathrm{mg} / \mathrm{kg}$ risperidone and $40 \mathrm{mg} / \mathrm{kg}$ resveratrol; RSV3 group, rats treated with $2 \mathrm{mg} / \mathrm{kg}$ risperidone and $80 \mathrm{mg} / \mathrm{kg}$ resveratrol.

RSV2 group was observed to have a weight loss and RSV3 group a weight gain had no significant effect on these measurements $(p>0.05)$ (Table 1, Figure 1).
Effects of RIS and RSV on biochemical and oxidative stress parameters

We measured levels of biochemical parameters in the serum, and the results are shown in Table 2. ALT, AST, GGT, LDL, $\mathrm{TG}$, and TCH levels significantly increased in the RIS group compared to control, RSV1, RSV2, and RSV3 groups while the HDL level decreased $(p<0.01)$. ALT, GGT, TG, and TCH levels were significantly lower in the RSV2 group compared to RSV1 group $(p<0.01)$. ALT, AST, GGT, and LDL levels were significantly lower in RSV3 group compared to RSV1 group while the HDL level increased $(p<0.02)$. LDL level was significantly lower in RSV3 group compared to RSV2 group $(p<0.03)$. LDL, TG, and CH levels were significantly lower in RSV2 group compared to Control group $(p<0.02)$. ALT, AST, LDL, TG, and TCH levels were significantly lower in RSV3 group compared to the Control group while the HDL level increased $(p<0.04)$ (Table 2, Figures 2 and 3 ).

Treatment with RSV against RIS administration while increased the TAS level, decreased TOS and OSI levels $(p<0.05)$. The TAS level was significantly increased in Control group when compared to the RIS group $(p=0.024)$. The TAS level was significantly increased in RSV1 group when compared to RIS, RSV2, and RSV3 groups $(p<0.04)$. Also, the TAS level was significantly higher in RSV2 group when compared to the RSV3 group $(p=0.019)$. Conversely, the TOS level was significantly increased in RIS group when compared to control, RSV1, RSV2, and RSV3 groups $(p<0.001)$. The TOS level was significantly increased in RSV1 group when compared to RSV3 group $(p=0.006)$. The OSI level was significantly higher in the RIS group when

Table 2. Comparision of serum biochemical and serum oxidative stress parameters among the study population

\begin{tabular}{|c|c|c|c|c|c|}
\hline & \multicolumn{5}{|c|}{ Group } \\
\hline & Control & RIS & RSV1 & RSV2 & RSV3 \\
\hline \multicolumn{6}{|c|}{ Biochemical parameters $(\mathrm{mg} / \mathrm{dl})$} \\
\hline ALT & $51.71 \pm 2.52^{\mathrm{b} 1, \mathrm{e} 2}$ & $60.00 \pm 2.40^{\mathrm{a} 1, \mathrm{c} 1, \mathrm{~d} 3, \mathrm{e} 3}$ & $51.85 \pm 1.92^{\mathrm{b} 1, \mathrm{e} 2}$ & $44.57 \pm 1.97^{b 3}$ & $41.71 \pm 3.63^{\mathrm{a} 2, \mathrm{~b} 3, \mathrm{c} 2}$ \\
\hline AST & $145.28 \pm 6.27^{\mathrm{b} 3, \mathrm{e} 2}$ & $172.71 \pm 4.79^{\mathrm{a} 3, \mathrm{c} 2, \mathrm{~d} 3, \mathrm{e} 3}$ & $152.00 \pm 3.70^{\mathrm{b} 2, \mathrm{~d} 2, \mathrm{e} 3}$ & $130.16 \pm 4.07^{\mathrm{b} 3, \mathrm{c} 2}$ & $122.00 \pm 5.83^{\mathrm{a} 2, \mathrm{~b} 3, \mathrm{c} 3}$ \\
\hline GGT & $4.28 \pm 0.28^{\mathrm{b} 3}$ & $6.42 \pm 0.36^{\mathrm{a} 3, \mathrm{c} 3, \mathrm{~d} 3, \mathrm{e} 3}$ & $4.85 \pm 0.26^{\mathrm{b} 3, \mathrm{~d} 1, \mathrm{e} 1}$ & $3.85 \pm 0.26^{\mathrm{b} 3, \mathrm{cl}}$ & $3.85 \pm 0.26^{\mathrm{b} 3, \mathrm{c} 1}$ \\
\hline HDL & $25.00 \pm 0.89^{\mathrm{b} 1, \mathrm{e} 2}$ & $21.00 \pm 0.48^{\mathrm{a} 1, \mathrm{c} 2, \mathrm{~d} 3, \mathrm{e} 3}$ & $25.85 \pm 0.88^{\mathrm{b} 2, \mathrm{e} 1}$ & $27.14 \pm 1.59^{\mathrm{b} 3}$ & $29.71 \pm 1.42^{\mathrm{a} 2, \mathrm{~b} 3, \mathrm{cl}}$ \\
\hline LDL & $13.00 \pm 0.43^{\mathrm{b} 3, \mathrm{~d} 2, \mathrm{e} 3}$ & $17.57 \pm 0.81^{\mathrm{a} 3, \mathrm{c} 3, \mathrm{~d} 3, \mathrm{e} 3}$ & $12.00 \pm 0.92^{\mathrm{b} 3, \mathrm{e} 3}$ & $10.42 \pm 0.42^{\mathrm{a} 2, \mathrm{~b} 3, \mathrm{e} 1}$ & $8.14 \pm 0.50^{\mathrm{a} 3, \mathrm{~b} 3, \mathrm{c} 3, \mathrm{~d} 1}$ \\
\hline TG & $45.00 \pm 1.74^{\mathrm{b} 3, \mathrm{~d} 2, \mathrm{e} 1}$ & $59.42 \pm 2.08^{\mathrm{a} 3, \mathrm{c} 3, \mathrm{~d} 3, \mathrm{e} 3}$ & $44.14 \pm 1.65^{\mathrm{b} 3, \mathrm{~d} 1}$ & $36.57 \pm 2.45^{\mathrm{a} 2, \mathrm{~b} 3, \mathrm{cl}}$ & $37.28 \pm 3.49^{\mathrm{a} 1, \mathrm{~b} 3}$ \\
\hline $\mathrm{TCH}$ & $46.85 \pm 2.32^{\mathrm{b} 1, \mathrm{~d} 2, \mathrm{e} 1}$ & $54.71 \pm 1.30^{\mathrm{a} 1, \mathrm{c} 2, \mathrm{~d} 3, \mathrm{e} 3}$ & $45.00 \pm 2.18^{\mathrm{b} 2, \mathrm{~d} 1}$ & $36.28 \pm 2.69^{\mathrm{a} 2, \mathrm{~b} 3, \mathrm{cl}}$ & $39.14 \pm 4.04^{\mathrm{a} 1, \mathrm{~b} 3}$ \\
\hline \multicolumn{6}{|c|}{ Total oxidant/antioxidant } \\
\hline TAS (mmol/l) & $1.74 \pm 0.38^{\mathrm{bl} 1, \mathrm{e} 3}$ & $0.92 \pm 0.17^{\mathrm{a} 1, \mathrm{c} 3}$ & $2.14 \pm 0.30^{\mathrm{b} 3, \mathrm{~d} 1, \mathrm{e} 3}$ & $1.38 \pm 0.09^{\mathrm{cl}, \mathrm{el}}$ & $0.52 \pm 0.12^{\mathrm{a} 3, \mathrm{c} 3, \mathrm{~d} 1}$ \\
\hline TOS $(\mu \mathrm{mol} / \mathrm{l})$ & $9.88 \pm 0.76^{\mathrm{b} 3, \mathrm{e} 1}$ & $15.90 \pm 1.06^{\mathrm{a} 3, \mathrm{c} 3, \mathrm{~d} 3, \mathrm{e} 3}$ & $10.30 \pm 1.07^{\mathrm{b} 3, \mathrm{e} 2}$ & $8.34 \pm 0.54^{\mathrm{b} 3}$ & $6.42 \pm 1.08^{\mathrm{a} 1, \mathrm{~b} 3, \mathrm{c} 2}$ \\
\hline OSI (AU) & $0.71 \pm 0.15^{\mathrm{b} 2}$ & $2.57 \pm 0.90^{\mathrm{a} 2, \mathrm{c} 2, \mathrm{~d} 2}$ & $0.52 \pm 0.07^{\mathrm{b} 2}$ & $0.62 \pm 0.05^{\mathrm{b} 2}$ & $1.57 \pm 0.48$ \\
\hline
\end{tabular}

Each group represents the mean $\pm \operatorname{SEM}(n=7) .{ }^{\mathrm{a}}$ significant from control; ${ }^{\mathrm{b}}$ significant from RIS; ${ }^{\mathrm{c}}$ significant from RSV1; ${ }^{\mathrm{d}}$ significant from RSV2; ${ }^{\mathrm{e}}$ significant from RSV3. ${ }^{1} p \leq 0.05,{ }^{2} p \leq 0.01,{ }^{3} p \leq 0.001$. AU, arbitrary units; TCH, total cholesterol; ALT, alanine aminotransferase; AST, aspartate aminotransferase; GGT, gamma glutamyl transpeptidase; HDL, high-density lipoprotein cholesterol; LDL, low density lipoprotein cholesterol; TG, triglycerides. For more abbreviations, see Table 1. 

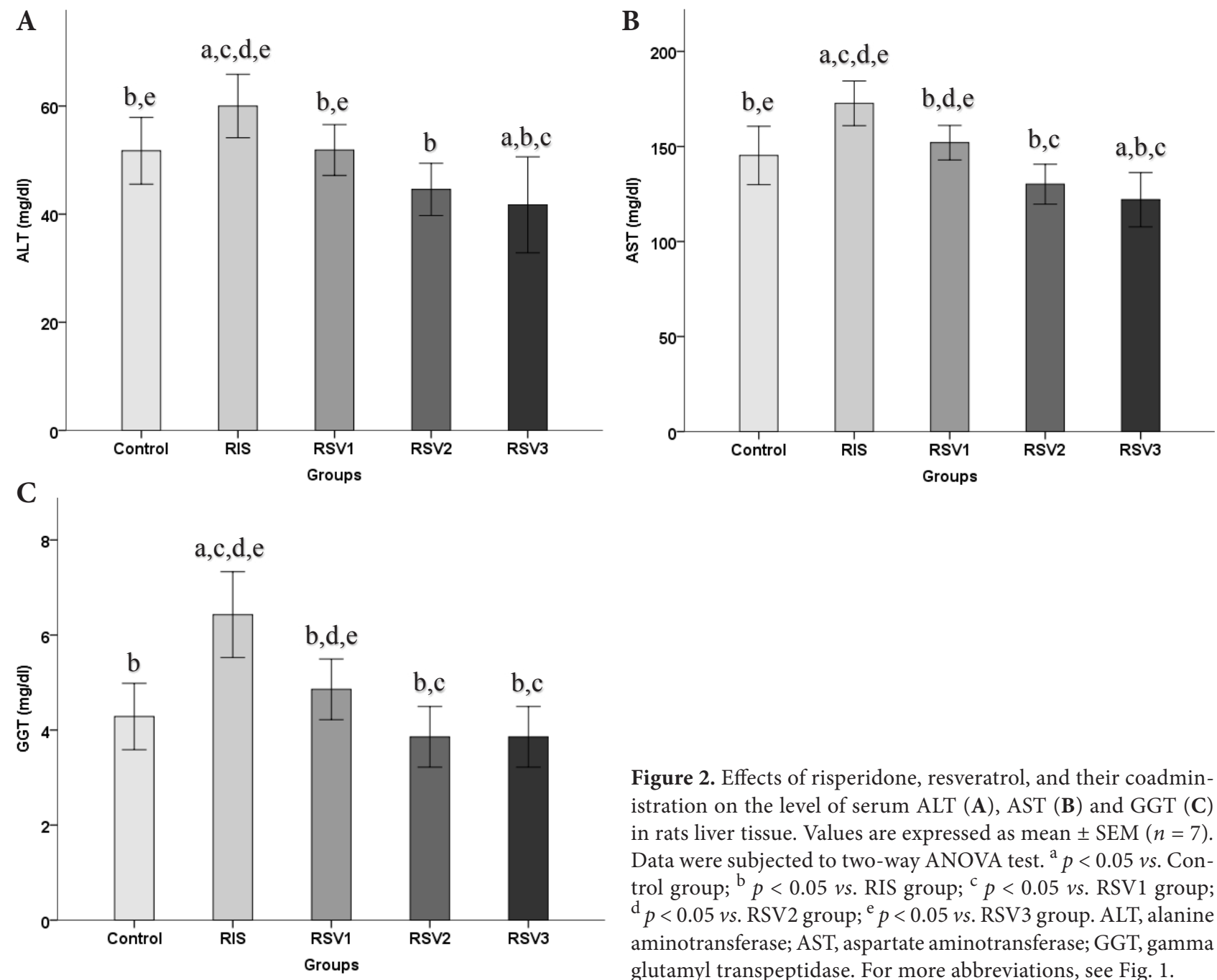

Figure 2. Effects of risperidone, resveratrol, and their coadministration on the level of serum ALT (A), AST (B) and GGT (C) in rats liver tissue. Values are expressed as mean $\pm \operatorname{SEM}(n=7)$. Data were subjected to two-way ANOVA test. ${ }^{\mathrm{a}} p<0.05 v s$. Control group; ${ }^{\mathrm{b}} p<0.05 v s$. RIS group; ${ }^{\mathrm{c}} p<0.05$ vs. RSV1 group; ${ }^{\mathrm{d}} p<0.05$ vs. RSV2 group; ${ }^{\mathrm{e}} p<0.05$ vs. RSV3 group. ALT, alanine aminotransferase; AST, aspartate aminotransferase; GGT, gamma glutamyl transpeptidase. For more abbreviations, see Fig. 1.

compared to control, RSV1, and RSV2 groups $(p<0.05)$ (Table 2, Figure 4).

\section{Effect of RIS and RSV on expression of the Fas gene}

Table 3 shows the effects of RSV treatment against the RIS administration on the mRNA expression of Fas gene level in all study groups and control. Fas gene expression significantly increased in RIS group compared to Control group. The RSV1 group had a significantly lower expression of Fas gene level compared to RIS group $(p \leq 0.01)$ (Table 3, Figure 5).

\section{Effect of RIS and RSV on apoptosis in rat liver}

The results of the apoptotic index are demonstrated in Table 4 and Figure 6. Using TUNEL for the detection of apoptotic cells in the liver sections, the Control group showed

only a few TUNEL-positive cells (Figure 6A). The count of TUNEL-positive cells significantly increased in the RIS group (Figure 6B) compared with that in Control group

Table 3. Effects of risperidone and resveratrol on the expression of FAS gene in rat liver

\begin{tabular}{ll}
\hline Group & \multicolumn{1}{c}{ FAS gene } \\
\hline Control & $15.35 \pm 0.32^{\mathrm{b} 2, \mathrm{~d} 1, \mathrm{el}}$ \\
RIS & $16.73 \pm 0.32^{\mathrm{a} 2, \mathrm{cl}}$ \\
RSV1 & $15.05 \pm 0.61^{\mathrm{b} 1, \mathrm{~d} 1, \mathrm{el}}$ \\
RSV2 & $17.03 \pm 0.31^{\mathrm{a} 1, \mathrm{cl}}$ \\
RSV3 & $17.00 \pm 0.22^{\mathrm{a} 1, \mathrm{c} 1}$ \\
\hline
\end{tabular}

Data are mean $\pm \operatorname{SEM}(n=7) .{ }^{\text {a }}$ significant from control; ${ }^{\mathrm{b}}$ significant from RIS; ${ }^{\mathrm{c}}$ significant from RSV 1 ; ${ }^{\mathrm{d}}$ significant from RSV2; ${ }^{\mathrm{e}}$ significant from RSV $3 ;{ }^{1} p \leq 0.05 ;{ }^{2} p \leq 0.01 ;{ }^{3} p \leq 0.001$. For abbreviations, see Table 1 . 
Table 4. Effects of risperidone and resveratrol on apoptotic index (AI) in rat liver

\begin{tabular}{ll}
\hline Group & \multicolumn{1}{c}{ AI $(\%)$} \\
\hline Control & $2.75 \pm 0.95^{\mathrm{b}, \mathrm{d}, \mathrm{e}}$ \\
RIS & $3.75 \pm 1.25^{\mathrm{a}, \mathrm{c}, \mathrm{e}}$ \\
RSV1 & $3.00 \pm 1.00^{\mathrm{b}}$ \\
RSV2 & $3.83 \pm 3.65^{\mathrm{a}}$ \\
RSV3 & $3.60 \pm 3.91^{\mathrm{a}, \mathrm{b}}$ \\
\hline
\end{tabular}

Data are mean \pm SD for seven rats in each group. ${ }^{a}$ significant from control; ${ }^{b}$ significant from RIS;

${ }^{c}$ significant from RSV1; ${ }^{d}$ significant from RSV2;

${ }^{\mathrm{e}}$ significant from RSV3 $(p \leq 0.05)$. For more abbreviations, see Table 1.
( $p<0.05$ ). RSV1 (Figure 6C), RSV2 (Figure 6D), and RSV3 (Figure 6E) groups were similar and showed rare TUNELpositive cells. Treatment with RSV (RSV1, RSV2, and RSV3 groups) (Figure $6 \mathrm{C}, 6 \mathrm{D}$, and $6 \mathrm{E}$ ) reduced the count of TUNEL-positive cells compared to the RIS group $(p<0.05)$.

\section{Discussion}

AAPs are used to treat serious mental disorders. Though they have many beneficial effects, they also have many serious side effects (Eder et al. 2001). RIS is one of the AAPs that has led to weight gain and obesity side-effects, and other
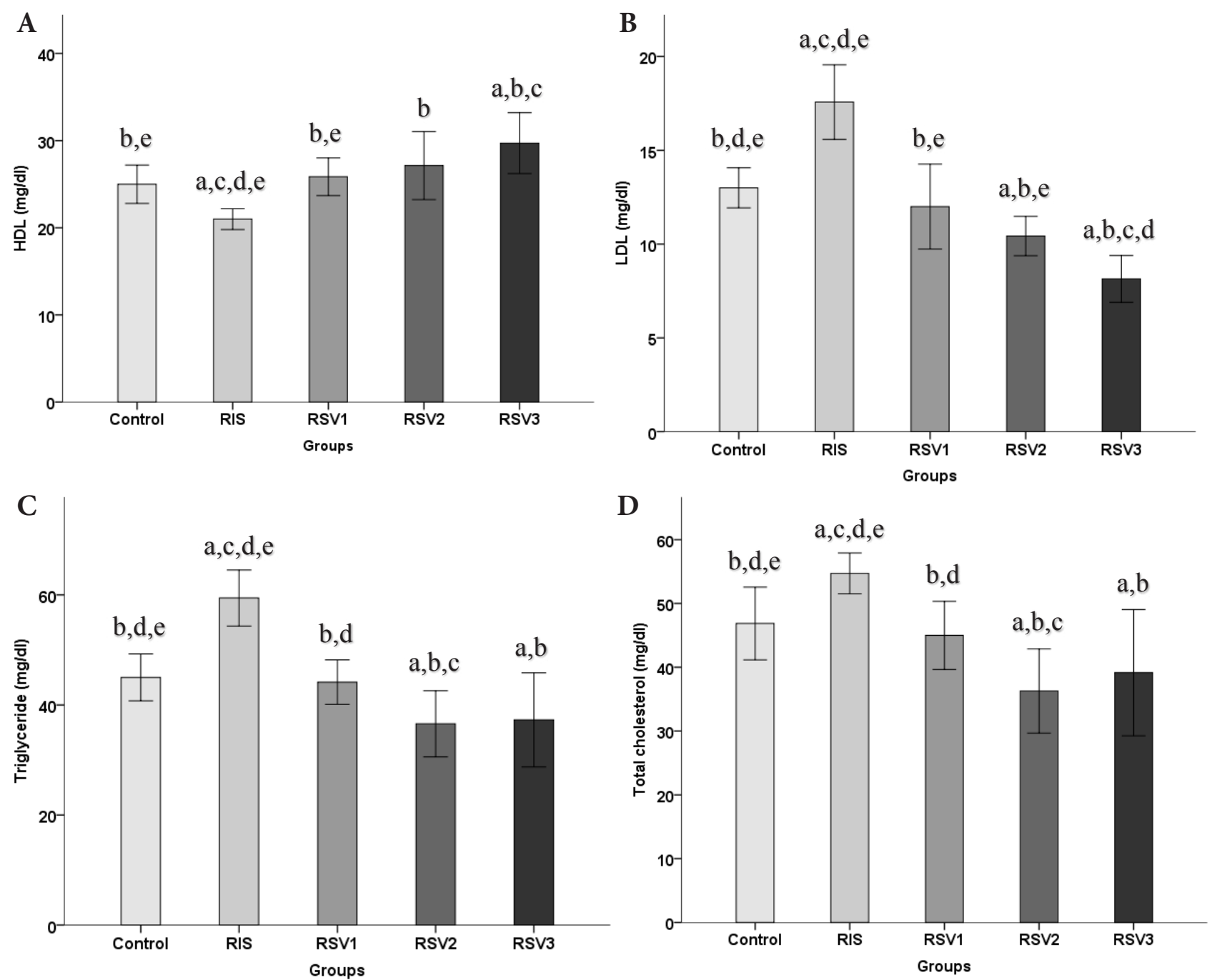

Figure 3. Effects of risperidone, resveratrol, and their coadministration on the level of serum HDL (A), LDL (B), TG (C) and TCH (D) in rats after two weeks. Values are expressed as mean \pm SEM $(n=7)$. Data were subjected to two-way ANOVA. ${ }^{\mathrm{a}} p<0.05 v s$. Control group; ${ }^{\mathrm{b}} p<0.05$ vs. RIS group; ${ }^{\mathrm{c}} p<0.05 v s$. RSV1 group; ${ }^{\mathrm{d}} p<0.05 v s$. RSV2 group; ${ }^{\mathrm{e}} p<0.05 v s$. RSV3 group. HDL, high-density lipoprotein cholesterol; LDL, low density lipoprotein cholesterol; TG, triglycerides; TCH, total cholesterol. For more abbreviations, see Fig. 1. 

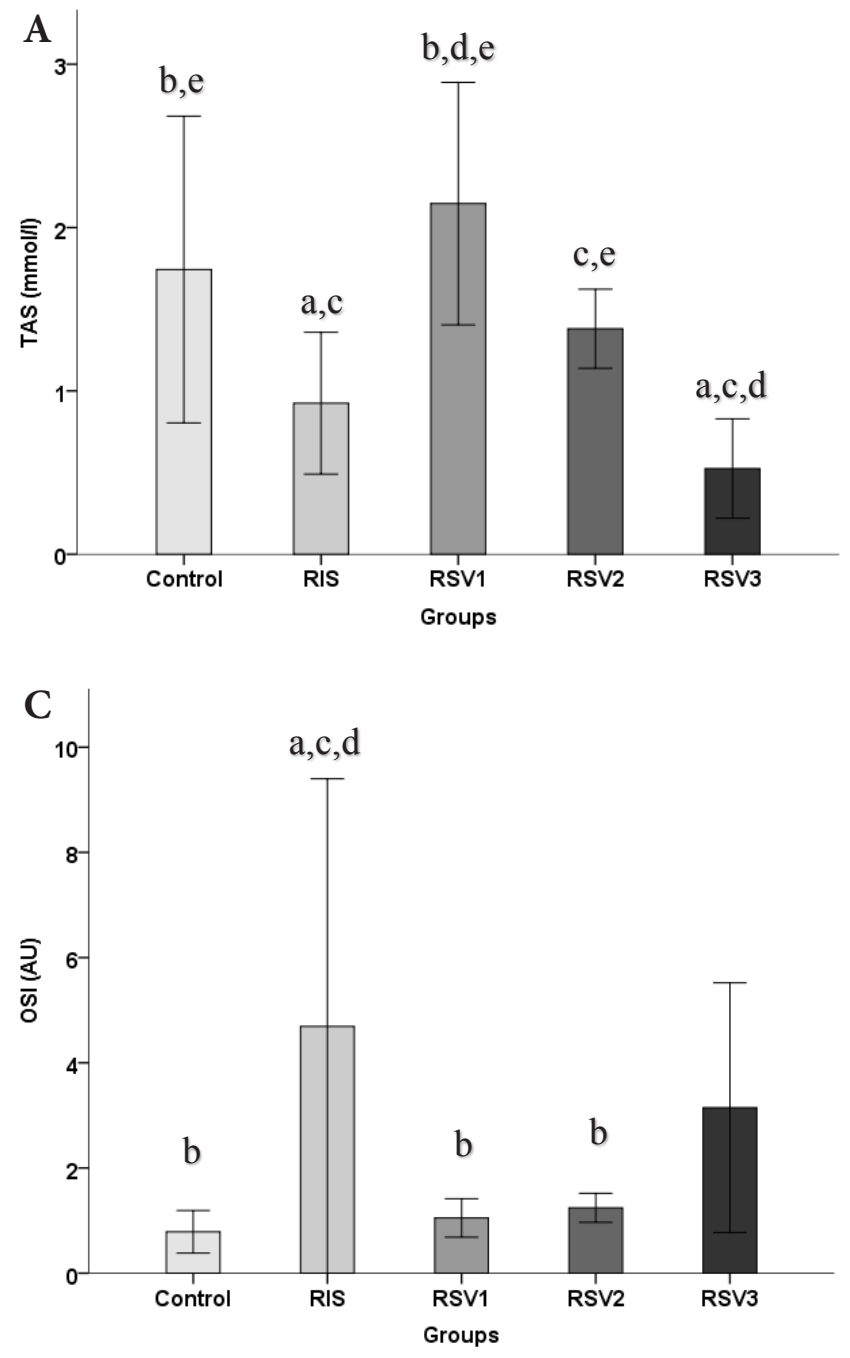

metabolic disorders in patients (Yoon et al. 2016). Therefore, it is extremely important to prevent side effects and other metabolic disorders induced by RIS. Many authors have suggested a co-treatment between RIS and compounds that regulate its metabolic adverse effects. Through antioxidant and radical scavenger properties of natural compounds may prevent and treat diseases. Dietary intake of natural compounds, including RSV, can inhibit the metabolic side effects of RIS and thereby may reduce the risk factors in the liver (Walton et al. 1999). Hence, the purpose of the current study was to investigate the protective and therapeutic effects of RSV against the effect of RIS over Fas gene expression and RIS-induced liver damage.

The liver is responsible for many vital life functions and is involved in uptake, secretion, synthesis, catabolism and storage. Fatty acids increase in the liver by hepatocellular uptake from the plasma and by de novo biosynthesis. Hepatic FAS is the synthesizing of fatty acids for the partitioning and

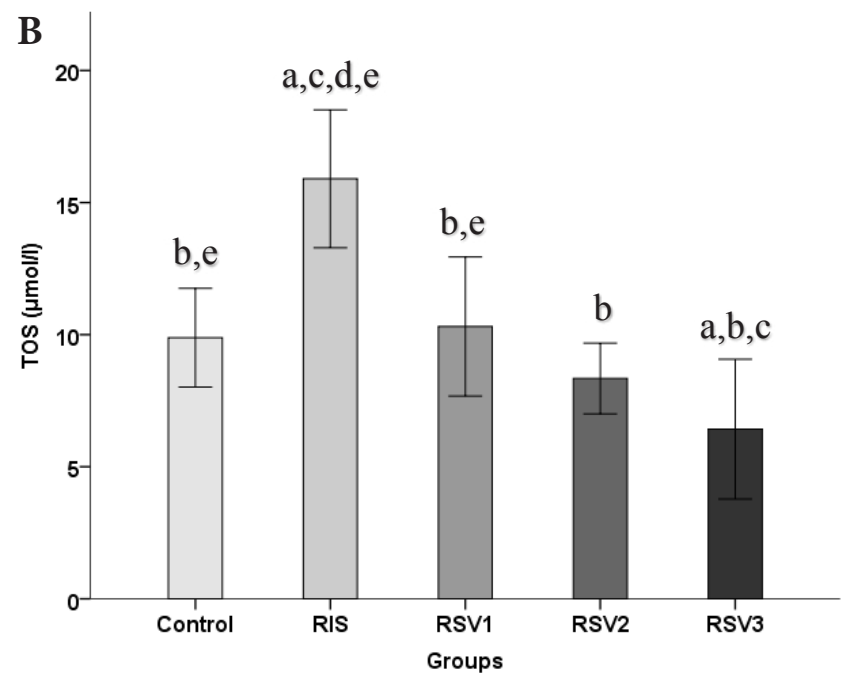

Figure 4. Effects of risperidone, resveratrol, and their coadministration on the level of TAS (A), TOS (B) and OSI (C) in rats after two weeks. Values are expressed as mean $\pm \operatorname{SEM}(n=7)$. Data were subjected to two-way ANOVA. ${ }^{\mathrm{a}} p<0.05 v s$. Control group; ${ }^{\mathrm{b}} p<0.05$ vs. RIS group; ${ }^{\mathrm{c}} p<0.05$ vs. RSV1 group; ${ }^{\mathrm{d}} p<0.05$ vs. RSV2 group; ${ }^{\mathrm{e}} p<0.05$ vs. RSV3 group. TAS, total antioxidant status; TOS, total oxidant status; OSI, oxidative stress index; AU, arbutrary units. For more abbreviations, see Fig. 1.

storage of excess energy (Jensen-Urstad and Semenkovich 2012). According to clinical experiences, an accumulation of extreme intracellular triglycerides often comes before the improvement of obesity (Riediger and Clara 2011). This study shows that RIS significantly increases the expression of the Fas gene, and there are highly meaningful correlations between the expression of this gene and the final body weight of animals. This effect of RIS was formerly presented in different experimental models of the liver (Cope et al. 2005; Lauressergues et al. 2011). In addition, high TG observed in rats subjected to RIS are a result of elevated hepatic FAS expression. Similarly, previous studies reported that rodent models with high triglyceride levels are related to increased hepatic FAS expression (Morgan et al. 2008). In this study, we conclude that the increase in observed body weight can be partially caused by elevated levels of circulating and stored TG. Taken together, RIS exposure can cause long-term hypertriglyceridemia due to the FAS-dependent pathway to 


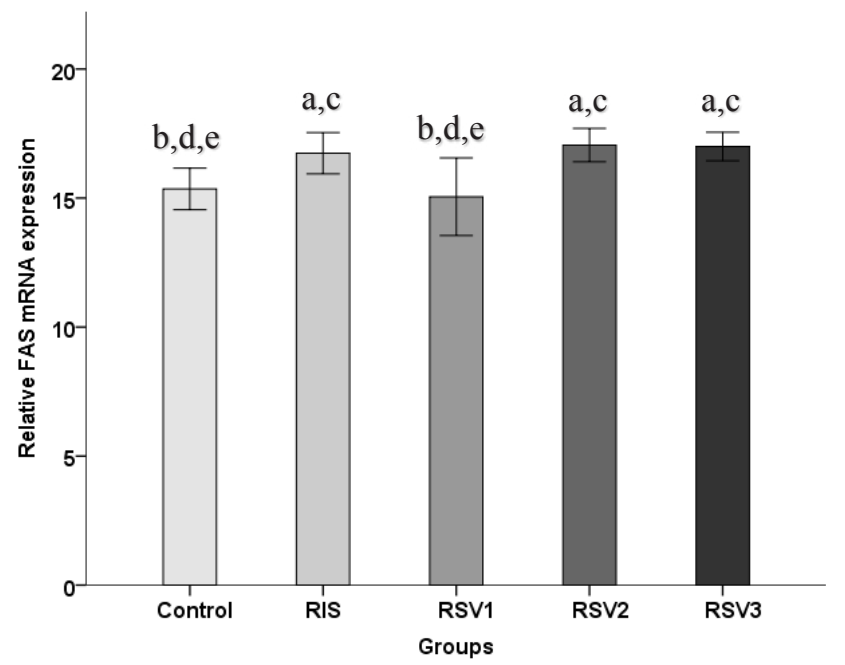

Figure 5. Effects of risperidone and RSV on the expression of fatty acid synthase (FAS) gene in rat liver. Data are means \pm SEM $(n=$ 7). Different letters over the bars represent significant differences, $p<0.05$. For more abbreviations, see Fig. 1 .

the synthesis of de novo TG. Thus, RIS-induced weight gain could be the result of the effect of RIS-associated alterations on the central nervous system, including on body temperature, on food intake, on locomotor activity.

RSV, a natural compound in superfoods like wine, has a beneficial effect on glucose and lipid metabolism. In fact, many clinical trials have recently demonstrated that using animal models of diet-induced obesity has displayed the beneficial effects of RSV on reducing obesity and oxidative stress (G'omez-Zorita et al. 2012; Farag et al. 2017). In addition, RSV performs a considerable role in lipid metabolism. In the current study, RSV co-treatment decreased antipsychoticinduced weight gain significantly with only a $20 \mathrm{mg} / \mathrm{kg}$ dose. Also, RSV attenuated hepatic triacylglycerol and fatty acid synthesis in rats. This data suggest that the RSV had protective effects against the adverse effects of RIS and decreased the risk of obesity. These results imply that the mechanism of effect of RSV occurs by increasing energy consumption, inhibition of energy intake, and reducing energy storage. This weight decreasing effect of RSV is estimated to be attributable, in part, to its effects on adipocytes and expression of the Fas gene (Baur et al. 2006; Naderali 2009). Therefore RSV is a reliable compound for co-administration with RIS for decrease of antipsychotic-induced weight gain and obesity without effecting its therapeutic action.

In the present study, RIS exposure produced a significant increase in the activity of liver enzymes. ALT, AST, and GGT indicate a damaged functional and structural hepatic integrity. Oral supplementation of RSV reduces liver injury and improves the elevated serum ALT, AST and GGT activities. While RSV co-treatment curable these changes in all doses, it had the most obvious effect in high doses. Our study results are confirmed by data from the literature (Miguel et al. 2016). In addition, we demonstrated that RSV prevented the increase in TG, TCH, and LDL as well as a decrease in HDL caused by RIS consumption. All doses of RSV caused dose-dependent decreases in serum lipids compared to RIS administrated rats. However, RSV co-treatment curable these changes with more obvious effect but with a major decrease in the $80 \mathrm{mg} / \mathrm{kg}$ dose. The effect of RSV on serum lipids has been reported in earlier experiments (Panico et al. 2017). This finding is probably a consequence of feeding behavior and the increase in body weight. Although underlying physiological pathways are not fully understood, the present findings indicate that RIS increases and RSV decreases serum lipids.

In this study, RSV significantly affected the RIS load on the liver, enhanced the reduced TAS, inhibited the elevated TOS and OSI levels, healed impaired hepatic function, and reformed the histopathological changes in the liver. RISmediated ROS formation by diminished antioxidant levels and oxidative stress and antioxidant depletion can lead to apoptotic cell death (Armstrong and Jones 2002). We found that RSV had a significant protective role in apoptotic cell death, which might be due to the ROS scavenging property. Taking the previous findings and suggestions together, it can be concluded that RSV could prevent RIS-induced liver injury and histological perturbations through the enhancement of antioxidant defense systems, suppression of oxidative stress, and attenuation of apoptosis. Oxidative stress has a vital role in the chain of initiation and progression of liver diseases. In this study, in RIS-administreted rats, a reduction in TAS level was observed resulting in a rise in TOS and OSI levels as in previous studies (Li et al. 2015). On the other hand, we observed that RSV protected against RIS-induced liver damage by suppressing oxidative stress and apoptosis. In addition, our results demonstrated that TAS levels increased and TOS, OSI levels conspicuously reduced with RSV treatment as reported in prior studies (Faghihzadeh et al. 2015). Additionally, the level of TAS significantly elevated with $20 \mathrm{mg} / \mathrm{kg}$ doses by RSV co-operation. Several studies have demonstrated that the hepatoprotective effect of RSV against liver damage is mediated by its antioxidant and anti-inflammatory properties (Bishayee et al. 2010). A few recent studies have shown that RSV-administered to mice in their diet significantly reduced lipids and depressed the expression of genes related to hepatic lipid metabolism (Ahn et al. 2008).

Histopathological findings support above oxidative results. The TUNEL assay used for determine apoptotic cells in the liver sections. Histopathological assessment of the liver showed serious damage followed by detrimental effects on the normal structure of the liver in RIS-administrated rats including vacuolar degeneration of hepatocytes and fatty 
changes. RIS-induced toxic effects were prevented through the powerful antioxidant capacity and other biological effects of RSV. Among the three doses, $80 \mathrm{mg}$ of RSV $/ \mathrm{kg}$ body weight was found to provide optimum protective effect on the liver against RIS-induced abnormal changes. Histological observations added more evidence supporting the protective effect of RSV. The present study demonstrated that RIS damaged the histological structure and function and inhibited the endogenous antioxidant defense system in rat liver tissue as reported in previous studies (Radzik et al. 2005). In addition, our results showed, at the first time, that RSV oral supplementation, at safe dose levels, has a noteworthy protective effect against RIS-induced liver damage in rats. This protection makes RSV a promising agent in a variety of conditions in which cellular damage occurs as a result of oxidative stress. RIS-induced liver injury causes increased ROS formation and subsequent toxic events. Accordingly, in our study, with RSV treatment of the cells against RIS
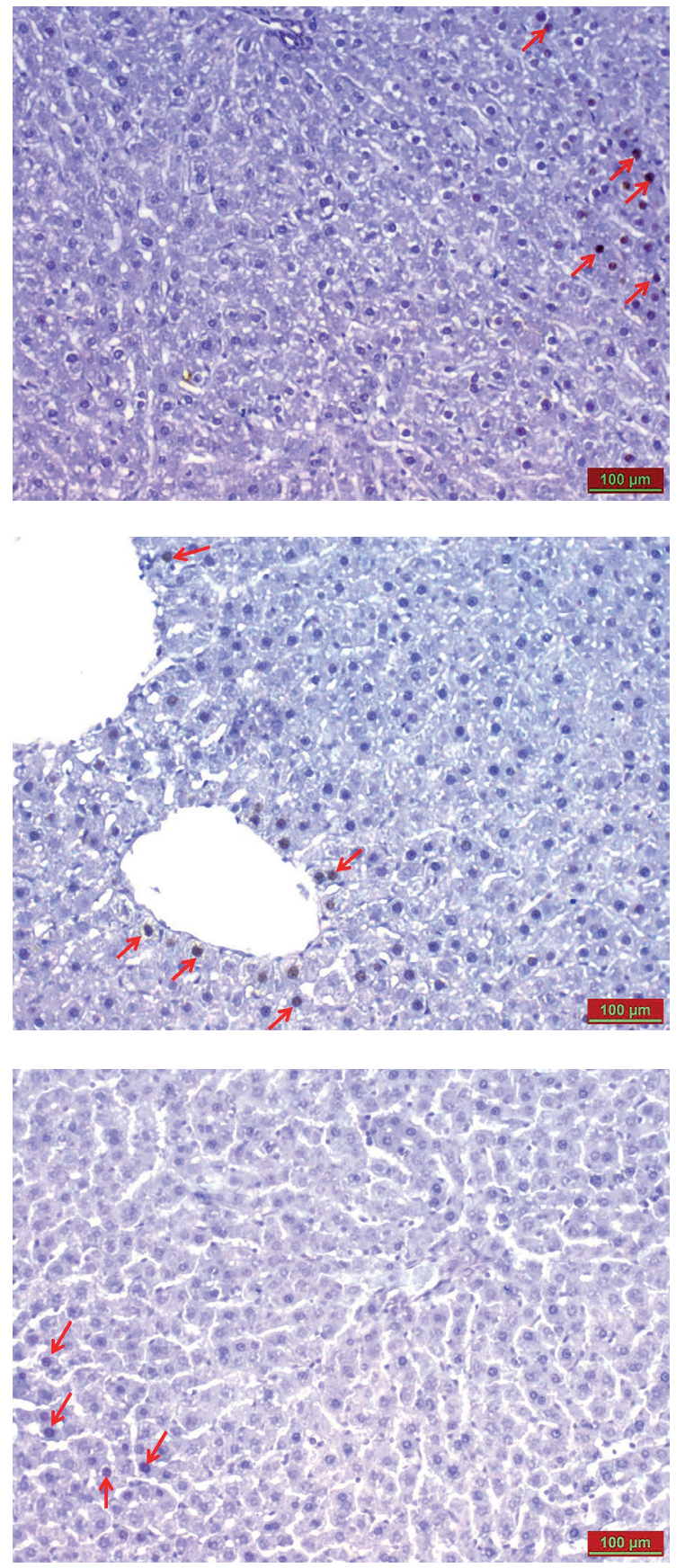
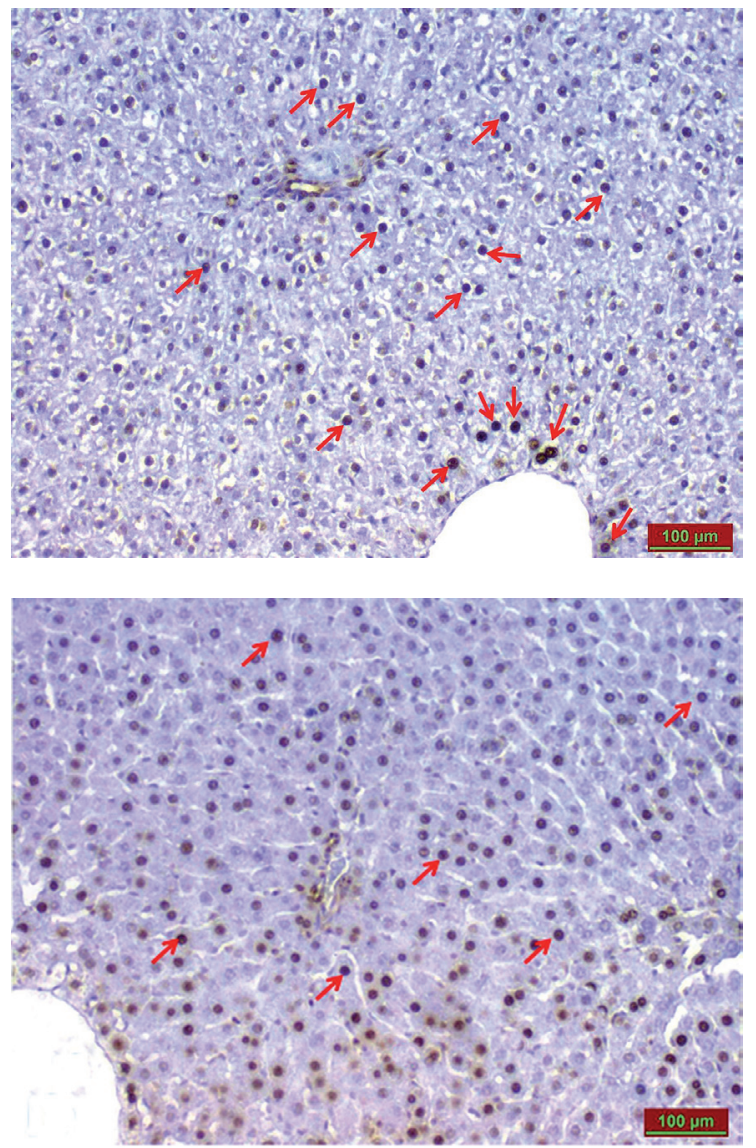

Figure 6. Representative photomicrographs of TUNEL staining of liver tissue after treatment of risperidone and resveratrol. A. Control group showing only few TUNELpositive cells (arrow). B. RIS group with a lot of TUNELpositive cells (arrows). RSV1 (C), RSV2 (D) and RSV3 (E) group showing similarly rare TUNEL-positive cells (arrows). This analysis was exerted in at least eight areas of each liver section (two sections/animal), and the sections were analyzed at $400 \times$ magnification. Scale bars $=100 \mu \mathrm{m}$. For more abbreviations, see Fig. 1. 
exposure, the apoptotic cell injury and death were greatly reduced. The underlying mechanism of the protective quality of RSV may be associated with the suppression of apoptosis via death receptor-mediated pathways. Therefore, previous studies show that antioxidant activity of RSV can be possible because of the effect on mitochondria-independent apoptotic pathways. Hence, RSV may be the best choice against RISinduced side effects.

In conclusion, RSV may be a promising agent to mitigate the adverse effects of RIS, oxidative stress, and apoptotic status and to reduce weight gain and the expression of the Fas gene and so prevent liver damage in patients. Thus, daily consumption of RSV should be considered as a promising way to prevent liver damage. Our results could be used to plan strategies to protect against the adverse effects of RIS in the liver and in other organs. Hence, further in vivo and clinical studies are required to confirm the protective effects of RSV in patients receiving RIS.

Conflict of interest. No potential conflicts of interest were reported.

\section{References}

Ahn J, Cho I, Kim S, Kwon D, Ha T (2008): Dietary resveratrol alters lipidmetabolism-related gene expression of mice on an athero-genic diet. J. Hepatol. 49, 1019-1028 https://doi.org/10.1016/j.jhep.2008.08.012

Armstrong JS, Jones DP (2002): Glutathione depletion enforces the mitochondrial permeability transition and causes cell death in Bcl-2 overexpressing HL60 cells. FASEB J. 16, $1263-1265$ https://doi.org/10.1096/fi.02-0097fje

Baur JA, Pearson KJ, Price NL, Jamieson HA, Lerin C, Kalra A, Prabhu VV, Allard JS, Lopez-Lluch G, Lewis K, et al. (2006): Resveratrol improves health and survival of mice on a high calorie diet. Nature 444, 337-342 https://doi.org/10.1038/nature05354

Bishayee A, Darvesh AS, Politis T, McGory R (2010): Resveratrol and liver disease: from bench to bedside and community. Liver İnternational 30, 1103-1114 https://doi.org/10.1111/j.1478-3231.2010.02295.x

Bou Khalil R (2012): Atypical antipsychotic drugs, schizophrenia, and metabolic syndrome in non-Euro-American societies. Clin. Neuropharmacol. 35, 141-147 https://doi.org/10.1097/WNF.0b013e31824d5288

Can N, Catak O, Turgut B, Demir T, Ilhan N, Kuloglu T, Ozercan IH (2015): Neuroprotective and antioxidant effects of ghrelin in an experimental glaucoma model. Drug Des. Devel Ther. 2, 2819-2829

Cope MB, Nagy TR, Fernández JR, Geary N, Casey DE, Allison DB (2005): Antipsychotic drug-induced weight gain: development of an animal model. Int. J. Obes. 29, 607-614 https://doi.org/10.1038/sj.ijo.0802928

Eder U, Mangweth B, Ebenbichler C, Weiss E, Hofer A, Hummer M, Kemmler G, Lechleitner M, Fleischhacker WW (2001): As- sociation of olanzapine-induced weight gain with an increase in body fat. Am. J. Psychiatry 158, 1719-1722 https://doi.org/10.1176/appi.ajp.158.10.1719

Erel O (2004): A novel automated method to measure total antioxidant response against potent free radical reactions. Clin. Biochem. 37, 112-119 https://doi.org/10.1016/j.clinbiochem.2003.10.014

Erel O (2005): A new automated colorimetric method for measuring total oxidant status. Clin. Biochem. 38, 1103-1111 https://doi.org/10.1016/j.clinbiochem.2005.08.008

Faghihzadeh F, Hekmatdoost A, Adibi P (2015): Resveratrol and liver: A systematic review. J. Res. Med. Sci. 20, 797-810 https://doi.org/10.4103/1735-1995.168405

Farag MR, Alagawany M, Tufarelli V (2017): In vitro antioxidant activities of resveratrol, cinnamaldehyde and their synergistic effect against cyadox-induced cytotoxicity in rabbit erythrocytes. Drug Chem. Toxicol. 40, 196-205 https://doi.org/10.1080/01480545.2016.1193866

Ferno J, Raeder MB, Vik-Mo AO, Skrede S, Glambek M, Tronstad KJ, Breilid H, Løvlie R, Berge RK, Stansberg C, Steen VM (2005): Antipsychotic drugs activate SREBP-regulated expression of lipid biosynthetic genes in cultured human glioma cells: a novel mechanism of action? Pharmacogenomics J. 5, 298-304 https://doi.org/10.1038/sj.tpj.6500323

Fukunishi S, Sujishi T, Takeshita A, Ohama H, Tsuchimoto Y, Asai A, Tsuda Y, Higuchi K (2014): Lipopolysaccharides accelerate hepatic steatosis in the development of nonalcoholic fatty liver disease in Zucker rats. J. Clin. Biochem. Nutr. 1, 39-44 https://doi.org/10.3164/jcbn.13-49

Gomez-Zorita S, Fernández-Quintela A, Macarulla MT, Aguirre L, Hijona E, Bujanda L, Milagro F, Martínez JA, Portillo MP (2012): Resveratrol attenuates steatosis in obese Zucker rats by decreasing fatty acid availability and reducing oxidative stress. Br. J. Nutr. 107, 202-210 https://doi.org/10.1017/S0007114511002753

Harma M, Harma M, Erel O (2005): Oxidative stress in women with preeclampsia. Am. J. Obstet. Gynecol. 192, 656-57 https://doi.org/10.1016/j.ajog.2004.07.094

Jensen-Urstad AP, Semenkovich CF (2012): Fatty acid synthase and liver triglyceride metabolism: housekeeper or messenger? Biochim. Biophys. Acta 1821, 747-753 https://doi.org/10.1016/j.bbalip.2011.09.017

Ji G, Zhao X, Leng L, Liu P, Jiang Z (2011): Comparison of dietary control and atorvastatin on high fat diet induced hepatic steatosis and hyperlipidemia in rats. Lipids Health Dis. 10, 23-33 https://doi.org/10.1186/1476-511X-10-23

Keck PE, McElroy SL,Strakowski SM, Soutullo CA (2000): Antipsychotics in the treatment of mood disorders and risk of tardive dyskinesia. J. Clin. Psychiatry 61, 33-38

Lauressergues E, Staels B, Valeille K, Majd Z, Hum DW, Duriez P, Cussac D (2010): Antipsychotic drug action on SREBPs-related lipogenesis and cholesterogenesis in primary rat hepatocytes. Naunyn Schmiedebergs Arch. Pharmacol. 381, 427-439 https://doi.org/10.1007/s00210-010-0499-4

Lauressergues E, Martin F, Helleboid A, Bouchaert E, Cussac $\mathrm{D}$, Bordet R et al. (2011): Overweight induced by chronic 
risperidone exposure is correlated with overexpression of the SREBP-1c and FAS genes in mouse liver. Naunyn-Schmied Arch. Pharmacol. 383, 423-436 https://doi.org/10.1007/s00210-010-0597-3

Li S, Tan HY, Wang N, Zhang ZJ, Lao L, Wong CW, Feng Y (2015) The role of oxidative stress and antioxidants in liver diseases. Int. J. Mol. Sci. 16, 26087-26124 https://doi.org/10.3390/ijms161125942

Martin AR, Villegas I, La Casa C, de la Lastra CA (2004): Resveratrol, apolyphenol found in grapes, suppresses oxidative damage and stimulates apoptosis during early colonic inflammation in rats. Biochem. Pharmacol. 67, 1399-1410 https://doi.org/10.1016/j.bcp.2003.12.024

Miguel NA, Andrade SF, Nai G, Laposy CB, Nascimento FF, Dinallo HR, Melchert A (2016): Effects of resveratrol on liver function of Obese female wistar rats. Cienc. anim. bras. 17, 402-410

Mobbs CV, Makimura H (2002): Block the FAS, lose the fat. Nat. Med. 8, 335-336 https://doi.org/10.1038/nm0402-335

Morgan K, Uyuni A, Nandgiri G, Mao L, Castaneda L, Kathirvel E, French SW, Morgan TR (2008): Altered expression of transcription factors and genes regulating lipogenesis in liver and adipose tissue of mice with high fat diet-induced obesity and nonalcoholic fatty liver disease. Eur. J. Gastroenterol Hepatol. 20, 843-854 https://doi.org/10.1097/MEG.0b013e3282f9b203

Naderali EK (2009): Obesity and cardiovascular dysfunction: a role for resveratrol. Obes. Res. Clin. Pract. 3, 45-52 https://doi.org/10.1016/j.orcp.2008.10.005

Ozelci KG, Aribal KP, Iren BD (2007): Resveratrol: Is there any effect on healthy subject? Biol. Trace Elem. Res. 118, 250-254 https://doi.org/10.1007/s12011-007-0033-9

Pal S, Ho N, Santos C, Dubois P, Mamo J, Croft K, Allister E (2003): Red wine polyphenolics increase LDL receptor expression and activity and suppress the secretion of ApoB100 from human HepG2 cells. J. Nutr. 133, 700-706 https://doi.org/10.1093/jn/133.3.700

Panico A, Lupoli GA, Lupoli R, Romano F, Barba L, Lupoli G (2017): Resveratrol improves the lipid profile promoted by red yeast rice (monacolin $\mathrm{k}$ ) in patients with moderate dyslipidemia: An open-label, randomized, parallel-group controlled clinical trial. The Euro Biotech Journal 1, 72-75 https://doi.org/10.24190/ISSN2564-615X/2017/01.11

Radzik J, Grotthus B, Leszek J (2005) Disorder of liver functions in a schizophrenic patient after long-term risperidone treatmentcase report. Psychiatr. Pol. 39, 309-313
Riediger ND, Clara I (2011): Prevalence of metabolic syndrome in the Canadian adult population. CMAJ 183, 1127-1134 https://doi.org/10.1503/cmaj.110070

Rummel-Kluge C, Komossa K, Schwarz S, Hunger H, Schmid S, Lobos CA, Kissling W, Davis JM, Leucht S (2010): Headto-head comparisons of metabolic side effects of second generation antipsychotics in the treatment of schizophrenia: a systematic review and meta-analysis. Schizophr. Res. 123, 225-233 https://doi.org/10.1016/j.schres.2010.07.012

Sul HS, Wang D (1998): Nutritional and hormonal regulation of enzymes in fat synthesis: studies of fatty acid synthase and mitochondrial glycerol-3-phosphate acyltransferase gene transcription. Annu. Rev. Nutr. 18, 331-351 https://doi.org/10.1146/annurev.nutr.18.1.331

Tas U, Ayan M, Sogut E, Kuloglu T, Uysal M, Tanriverdi HI, Senel U, Ozyurt B, Sarsilmaz M (2015): Protective effects of thymoquinone and melatonin on intestinal ischemia-reperfusion injury. Saudi J. Gastroenterol. 21, 284-289 https://doi.org/10.4103/1319-3767.166203

Yoon Y, Wink LK, Pedapati EV, Horn PS, Erickson CA (2016): Weight gain effects of second-generation antipsychotic treatment in autism spectrum disorder. J. Child Adolesc. Psychopharmacol. 26, 822-827 https://doi.org/10.1089/cap.2016.0049

Walton K, Walker R, van de Sandt JJ, Castell JV, Knapp AG, Kozianowski G, Roberfroid M, Schilter B (1999): The application of in vitro data in the derivation of the acceptable daily intake of food additives. Food Chem. Toxicol. 37, 1175-1197 https://doi.org/10.1016/S0278-6915(99)00107-6

Wakil SJ (1989): The fatty acid synthase: a proficient multifunctional enzyme. Biochemistry 28, 4523-4530 https://doi.org/10.1021/bi00437a001

Zhang X, Zhang Z, Cheng W, Mou X, Reynolds GP (2007): The effect of chronic antipsychotic treatment on sexual behaviour, hormones and organ size in the male rat. J. Psychopharmacol. 21, 428-434 https://doi.org/10.1177/0269881106068702

Zhao H, Li X, Li N, Liu T, Liu J, Li Z, Xiao, H, Li J (2014): Longterm resveratrol treatment prevents ovariectomy-induced osteopenia in rats without hyperplastic effects on the uterus. Br. J. Nutr. 111, 836-846 https://doi.org/10.1017/S0007114513003115

Received: June 28, 2018

Final version accepted: November 12, 2018 